Journal of Medical Genetics 1989, 26, 469-472

\section{Ring chromosome 15 in a patient with features of Fryns' syndrome}

SUMMARY A stillborn male infant with a ring chromosome 15 and some features compatible with Fryns' syndrome is presented. Neither diagnosis is common and the overlap may be of significance.

\section{History}

Prenatal. No drugs or infections in pregnancy. Mother had no antenatal care.

Birth. Normal vertex delivery at 38 weeks after sudden antepartum haemorrhage and cessation of fetal movements. Birth weight $2000 \mathrm{~g}$ ( $<3$ rd centile), head circumference $30 \mathrm{~cm}$ (<3rd centile), and length $44.3 \mathrm{~cm}$ ( $<3$ rd centile). The stillborn male infant was meconium stained and the cord was wound tightly around the neck. The amount of amniotic fluid was not recorded.

Family history. Normal, healthy, non-consanguineous 'Cape Coloured' parents; mother and father 37 and 38 years old, respectively. Normal older brother, but the younger brother had unilateral Perthes' disease of the hip and haemophilia B. All were dissimilar in appearance to the patient.

\section{Clinical features}

He had brachycephaly, a large posterior fontanelle, coarse looking facies, low set, large ears with poorly shaped auricles, short palpebral fissures, short philtrum, large, carp shaped mouth, and micrognathia (fig 1). Widely spaced nipples gave the appearance of a broad chest. The limbs showed brachydactyly, abnormal palmar creases, and rockerbottom feet, but no finger nail hypoplasia. He had cryptorchidism, but a well developed scrotum and short penis $(0.5 \mathrm{~cm})$.

\section{Investigations}

Necropsy. Left diaphragmatic hernia with lung hypoplasia (weight of right lung $=4.7 \mathrm{~g}$, left $=1.2 \mathrm{~g}$ ) and small dysplastic kidneys.

Chromosome analysis. 46,XY, $\mathrm{r}(15)(\mathrm{p} 11 \rightarrow \mathrm{q} 26)$ (fig 2). Chromosome complements of mother and both brothers normal. Father unavailable for chromosome studies. The ring appeared stable in all nine cells analysed from blood lymphocytes. No other tissue was available.

\section{Discussion}

A specific phenotype, namely slight to moderate mental retardation, pre- and postnatal growth failure, triangular
Fig 1 AP and lateral view of the patient showing hypertelorism, carp shaped mouth, low set, simple ears, micrognathia, and absence of medial eyebrows. 


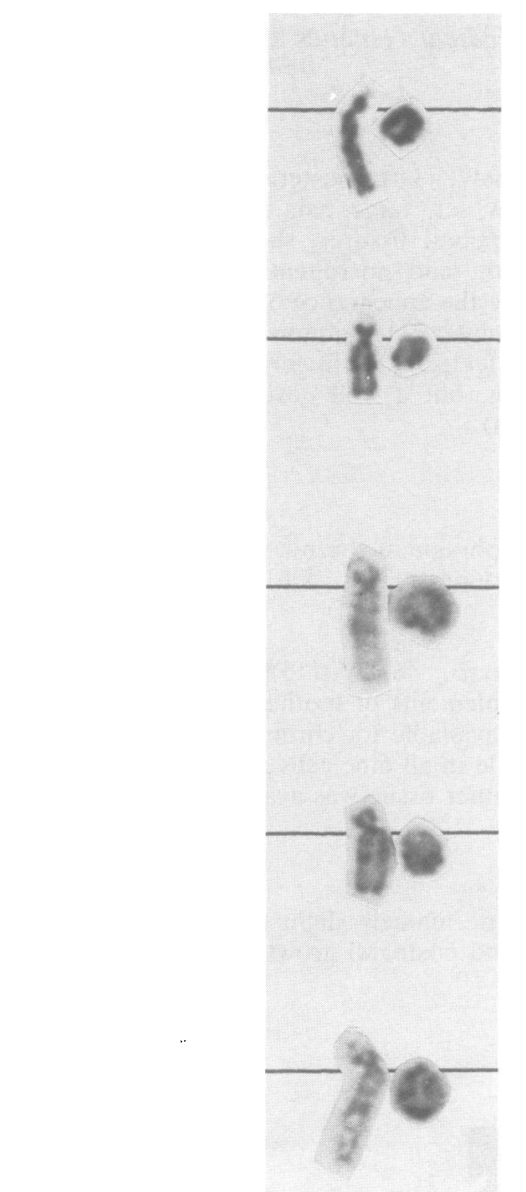

FIG $2 G$ banded partial karyotype of the ring chromosome $r(15)(q 26 \rightarrow q t e r)$ and its normal homologue.

facies, and short hands and feet, has been associated with ring chromosome $15 .{ }^{1}$ Two thirds of published cases had few or no dysmorphic stigmata, but growth failure and survival seemed to be the rule. ${ }^{2}$

Recently two sibs (a liveborn infant and a 13 week fetus) with a $(15 \mathrm{q} 24 \rightarrow$ qter $)$ deletion, both with diaphragmatic hernias and lung hypoplasia, were reported. ${ }^{3}$ The first infant was slightly dysmorphic with low set ears, club feet, and cryptorchidism, and was small for gestational age. The fetus had one umbilical artery and dysplastic kidneys.

All the physical features of our patient, except the growth failure and absence of nail hypoplasia, have been noted in Fryns' syndrome. No chromosome abnormalities have been reported in other cases of Fryns' syndrome. Growth failure is present in $20 \%$ of our neonates, but the patient's appearance is incompatible with his ancestry and suggests a syndromal component. The questions arise of whether the anomalies of diaphragmatic hernia, dysplastic kidneys, and dysmorphism are the result of the ring $15 \stackrel{?}{=}$ and whether this patient has Fryns' syndrome. The latter is a rare syndrome, not yet reported from this country. If the patient has Fryns' syndrome, could this be the result of monosomy of the recessive gene on the morphologically normal chromosome?

The authors wish to thank the Cape Provincial Administra- $\frac{0}{\infty}$ tion, the South African Medical Research Council, and the University of Stellenbosch for their support. The secretarial . assistance of Mrs M Page is gratefully acknowledged. We would like to thank $\operatorname{Dr} M$ Nelson for reviewing the manuscript and for helpful suggestions.

G DE JoNG, R A Rossouw, AND

A E ReTIEF $M R C$ Research Unit for Cytogenetics, Medical School, University of Stellenbosch, Tygerberg, Republic of South Africa.

\author{
References \\ ${ }^{1}$ Fryns JP, Timmermans J, D'Hondt F, Francois B, Emmery L, \\ Van den Berghe $\mathrm{H}$. Ring chromosome 15 syndrome. Hum Genet \\ 1979;51:43-8. \\ 2 Kosztolányi G, Pap M. Severe growth failure associated with \\ atrophic intestinal mucosa and ring chromosome 15. Acta \\ Paediatr Scand 1986;75:326-31. \\ 3 Kristoffersson U, Hein S, Mandahl N, Sundkvist L, Szelest J, \\ Hägerstrand I. Monosomy and trisomy of $15 \mathrm{q} 24 \rightarrow$ qter in a \\ family with a translocation $t(6 ; 15)(p 25 ; q 24)$. Clin Genet 1987 \\ 32:169-71.
}

Correspondence to Dr G de Jong, MRC Research Unit for Cytogenetics, Medical School, University of Stellenbosch, PO Box 63, Tygerberg, Republic of South Africa.

\section{Unknown syndrome: Noonan-like craniofacial features, digital anomalies, and premature birth}

SUMmARY We report a mother and two of her children, one female and the other male, who have ptosis, hypertelorism, epicanthic folds, downward slanting palpebral fissures, broad nasal bridge, and minor digital anomalies (fig 1); the children had delayed closure of a large anterior fontanelle. All three affected persons were born prematurely.

\section{History}

The normally intelligent mother was born six weeks prematurely when her father was aged 33 years, and was 